\title{
Prediction of extubation outcome
}

\section{in critically ill patients: a systematic review and meta-analysis}

\author{
Flavia Torrini ${ }^{1,2 \dagger}$, Ségolène Gendreau ${ }^{1,2+} \mathbb{C}^{\mathbb{C}}$, Johanna Morel ${ }^{1,2}$, Guillaume Carteaux ${ }^{1,2,3}$, Arnaud W. Thille ${ }^{4,5}$, \\ Massimo Antonelli ${ }^{6}$ and Armand Mekontso Dessap ${ }^{1,2,3^{*}}$
}

\begin{abstract}
Background: Extubation failure is an important issue in ventilated patients and its risk factors remain a matter of research. We conducted a systematic review and meta-analysis to explore factors associated with extubation failure in ventilated patients who passed a spontaneous breathing trial and underwent planned extubation. This systematic review was registered in PROPERO with the Registration ID CRD42019137003.
\end{abstract}

Methods: We searched the PubMed, Web of Science and Cochrane Controlled Register of Trials for studies published from January 1998 to December 2018. We included observational studies involving risk factors associated with extubation failure in adult intensive care unit patients who underwent invasive mechanical ventilation. Two authors independently extracted data and assessed the validity of included studies.

Results: Sixty-seven studies (involving 26,847 participants) met the inclusion criteria and were included in our metaanalysis. We analyzed 49 variables and, among them, we identified 26 factors significantly associated with extubation failure. Risk factors were distributed into three domains (comorbidities, acute disease severity and characteristics at time of extubation) involving mainly three functions (circulatory, respiratory and neurological). Among these, the physiological respiratory characteristics at time of extubation were the most represented. The individual topic of secretion management was the one with the largest number of variables. By Bayesian multivariable meta-analysis, twelve factors were significantly associated with extubation failure: age, history of cardiac disease, history of respiratory disease, Simplified Acute Physiologic Score II score, pneumonia, duration of mechanical ventilation, heart rate, Rapid Shallow Breathing Index, negative inspiratory force, lower $\mathrm{PaO}_{2} / \mathrm{FiO}_{2}$ ratio, lower hemoglobin level and lower Glasgow Coma Scale before extubation, with the latest factor having the strongest association with extubation outcome.

Conclusions: Numerous factors are associated with extubation failure in critically ill patients who have passed a spontaneous breathing trial. Robust multiparametric clinical scores and/or artificial intelligence algorithms should be tested based on the selected independent variables in order to improve the prediction of extubation outcome in the clinical scenario.

\footnotetext{
${ }^{*}$ Correspondence: armand.dessap@aphp.fr

${ }^{\dagger}$ Flavia Torrini and Ségolène Gendreau have contributed equally to this work

${ }^{1}$ Service de Médecine Intensive Réanimation, Hôpitaux Universitaires Henri Mondor, AP-HP, 1 rue Gustave Eiffel, 94010 Créteil Cedex, France Full list of author information is available at the end of the article
}

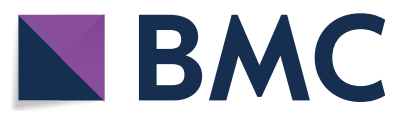

(c) The Author(s) 2021. Open Access This article is licensed under a Creative Commons Attribution 4.0 International License, which permits use, sharing, adaptation, distribution and reproduction in any medium or format, as long as you give appropriate credit to the original author(s) and the source, provide a link to the Creative Commons licence, and indicate if changes were made. The images or other third party material in this article are included in the article's Creative Commons licence, unless indicated otherwise in a credit line to the material. If material is not included in the article's Creative Commons licence and your intended use is not permitted by statutory regulation or exceeds the permitted use, you will need to obtain permission directly from the copyright holder. To view a copy of this licence, visit http://creativecommons.org/licenses/by/4.0/. The Creative Commons Public Domain Dedication waiver (http://creativeco mmons.org/publicdomain/zero/1.0/) applies to the data made available in this article, unless otherwise stated in a credit line to the data. 
Keywords: Airway extubation, Ventilator weaning, Risk factors

\section{Background}

As mechanical ventilation is associated with complications (e.g., ventilator-associated pneumonia) [1], the optimal time to wean patients from mechanical ventilation is a critical goal to achieve in intensive care unit (ICU) [2]. The decision to extubate is therefore usually taken as soon as a patient meet predefined weaning criteria and successfully pass a spontaneous breathing trial (SBT) [3]. Nevertheless, in $10-20 \%$ of patients who pass a spontaneous breathing trial and undergo planned extubation, extubation failure still occurs.

Extubation failure is usually defined as the need for reintubation within hours or days after a planned extubation. The time considered varies from $24 \mathrm{~h}[4,5]$ until any time during the hospital stay [6,7]. Extubation failure is associated with an overall increase in the duration of mechanical ventilation, a greater need for tracheostomy, higher medical costs and a $25-50 \%$ increased mortality rate [8-12]. There is some evidence that extubation failure is not just a marker of a more severe illness, but independently affects patients survival regardless of underlying illness severity $[9,13]$.

Unfortunately, the pathophysiology of extubation failure is not yet fully understood and a simple tool for predicting extubation failure is not available. Some studies suggested that the use of standardized weaning protocols reduced the total time of mechanical ventilation $[14,15]$ but the parameters that should be included in weaning protocols still remain controversial. Considering the complications associated with both a too early and delayed liberation from mechanical ventilation, the identification of robust risk factors for extubation failure would be extremely helpful in order to optimize the weaning process.

We therefore decided to conduct a systematic review of the literature and a meta-analysis to search risk factors associated with extubation failure, in adult critically ill patients who passed a SBT and underwent a planned extubation.

\section{Methods}

\section{Search strategy and selection criteria}

We performed this study in accordance with the Preferred Reporting Items for Systematic Reviews and Meta-Analyses (PRISMA) statement [16]. We searched PubMed, Web of Science and Cochrane controlled register of trials (CENTRAL) to identify articles on risk factors for extubation failure from January 1998 to
December 2018. We used the following search algorithm: (extubation) AND (success OR failure OR factor OR predictor OR prediction OR risk OR score OR outcome OR mortality OR reintubation OR intensive care unit).

We included all studies that evaluated any risk factors for extubation failure in adult (at least 18 years old) ICU patients under invasive mechanical ventilation. We excluded studies in children and animals and studies not written in English. References of all selected articles were scanned for additional relevant manuscripts. This study was registered in the International Prospective Register of Systematic Reviews (PROSPERO) database (Registration Number CRD42019137003). Ethical approval was not required.

\section{Data analysis}

After the removal of the duplicates, two authors (FT, JM) independently screened titles and abstracts to obtain relevant articles for full text review. We obtained the full text of all potentially relevant studies and the authors independently decided for final inclusion in the review. We also reviewed the references of relevant articles to avoid missing any studies. Any disagreement was resolved by consensus or discussion with a third reviewer (AMD).

The review authors independently extracted data. The following data were recorded from each selected study: year of publication, study design, baseline characteristics of the population (age, comorbidities), severity scores on ICU admission and stay [Severity Acute Physiologic Score (SAPS), Acute Physiology and Chronic Health Evaluation (APACHE)], medications, characteristics of the SBT, definition of extubation failure, risk factors associated with extubation failure (respiratory, cardiovascular, neurologic, laboratory parameters) and primary outcome (extubation failure). We further excluded risk factors with excessive missing data (reported in less than $10 \%$ of studies; see Additional file 1: Table S1 in the additional material). Study quality was assessed in terms of risk of bias using the QUIPS tool for prognostic studies (Cochrane), rating the potential risk of bias as high, moderate or low for each of six domains, namely study participation, study attrition, prognostic factor measurement, outcome measurement, study confounding, statistical analysis and reporting. Two authors (FT, JM) independently assessed the risk of bias, implying a third author in case of disagreement (AMD). 


\section{Statistical analysis}

We conducted a meta-analysis of observational prospective and retrospective studies. Data were summarized using medians and interquartile ranges (IQRs) or mean \pm standard deviation (SD) were appropriate [17]. For binary variables, the odds ratio (OR) with $95 \%$ confidence interval (CI) was calculated for extubation failure. For continuous variables, we calculated the mean difference with $95 \%$ CI between extubation success and extubation failure groups. A natural $\log$ transformation of OR (lnOR) was derived from crude OR (for binary variables) $[18,19]$ and from standardized mean differences (for continuous variables) [19] in a symmetric scale, from minus infinity, to infinity, with zero defining no effect [18], to allow comparison between categorical and numeric variables.

We adopted the inverse variance method for developing weights for individual study effects. We quantified heterogeneity using $I^{2}$ and $Q$ statistics, with values greater than $50 \%$ regarded as being indicative of moderate-to-high heterogeneity [20]. We used a random effect model to assess the population average mean difference and $95 \% \mathrm{CI}$ or OR and $95 \% \mathrm{CI}$ for all the risk factors for extubation failure. In order to measure the dispersion of the pooled effect across study settings, we generated predictions intervals [21].

We performed prespecified subgroup analyses according to the type of ICU patients, e.g., medical, surgical, mixed, neurological or other type of ICU. A heatmap was created to present lnOR (scaled to adjust for extreme values) for each variable according to ICU type. We conducted a sensitivity analysis including only studies referring to the most used definition of extubation failure (death or reintubation within $48 \mathrm{~h}$ from extubation), to explore if it changed the significance of the results. Another sensitivity analysis focused on studies referring to death or reintubation (whatever the delay).

A multivariable meta-analysis of multiple factors was secondarily performed with variables significantly associated with extubation outcome, using effect sizes as $\operatorname{lnOR}[22]$ and the altmeta package for $\mathrm{R}[23,24]$. Among related significant univariate factors, only the most statistically robust (as per the $\operatorname{lnOR}$ ), yet clinically relevant were entered into the models in order to minimize the effect of collinearity. Individual study effects and pooled effects were visualized through forest plots.

Publication biases were assessed graphically through funnel plot asymmetry [25]. Data were pooled and analyzed using Review Manager (Cochrane TC. Review Manager 5.3. Cph Nord Cochrane Cent, 2008) with a two-sided significance level of $5 \%$, and R 3.1.2 (The R Foundation for Statistical Computing, Vienna, Austria).

\section{Results}

Studies

We identified a total of 12,921 references from our searches (Fig. 1). After removing 4833 duplicates, we screened the titles and abstracts of 8088 articles, of which 7927 were excluded. The full texts of 161 studies were reviewed and 94 were excluded. Thus, we included 67 studies in the narrative review, and 66 studies were included in the quantitative synthesis. Of the 67 studies included in the review, 50 were prospective observational studies $[4-6,9,12,13,26-69]$ and 17 were retrospective studies [7, 70-85]. Fifty-seven studies were monocentric and ten were multicentric. Studies took place in medical $(n=19)$, surgical $(n=9)$, mixed $(n=28)$ and neurological $(n=11)$ ICUs.

We included 67 studies involving 26,847 participants in the meta-analysis. The type of SBT and the definition of extubation failure varied among the included studies (Table 1). SBT types included: multiple choice for SBT ( $n=15$, with 4 studies allowing CPAP and 14 studies allowing T-tube), low pressure support with low positive end expiratory pressure $(n=30)$, flow-by $(n=1)$, standard pressure support ventilation $(n=1)$, proportional assist ventilation $(n=1)$ and automatic tube compensation with low PEEP $(n=1)$. Extubation failure was defined either as death or reintubation within hours to days after extubation ( $24 \mathrm{~h}, 48 \mathrm{~h}, 72 \mathrm{~h}$ or 7 days in $4,30,14$ and 5 studies, respectively), or as the reinstitution of any mechanical ventilation after extubation, either invasive or noninvasive with a curative indication (10 studies).

\section{Risk factors for extubation failure}

Among the 49 variables analyzed, we found 26 variables significantly associated with extubation outcome, distributed into three domains [comorbidities $(n=5)$, acute disease severity $(n=6)$ and characteristics at time of extubation $(n=15)$ ] (Table 2, Fig. 2$)$ involving mainly three functions [respiratory $(n=16)$, circulatory $(n=3)$ and neurological $(n=1)$ ]; see Additional file 1: Fig. S1 in the additional material).

\section{Comorbidities}

We found a higher risk of extubation failure in older patients. Chronic obstructive respiratory disease, history of chronic cardiac or respiratory disease were associated with a higher risk of extubation failure as well. In contrast, a higher body mass index was associated with successful extubation.

\section{Acute disease severity}

Patients who failed extubation also differed from patients who succeeded in terms of acute disease severity, with higher values of SAPS II and APACHE II score in the 


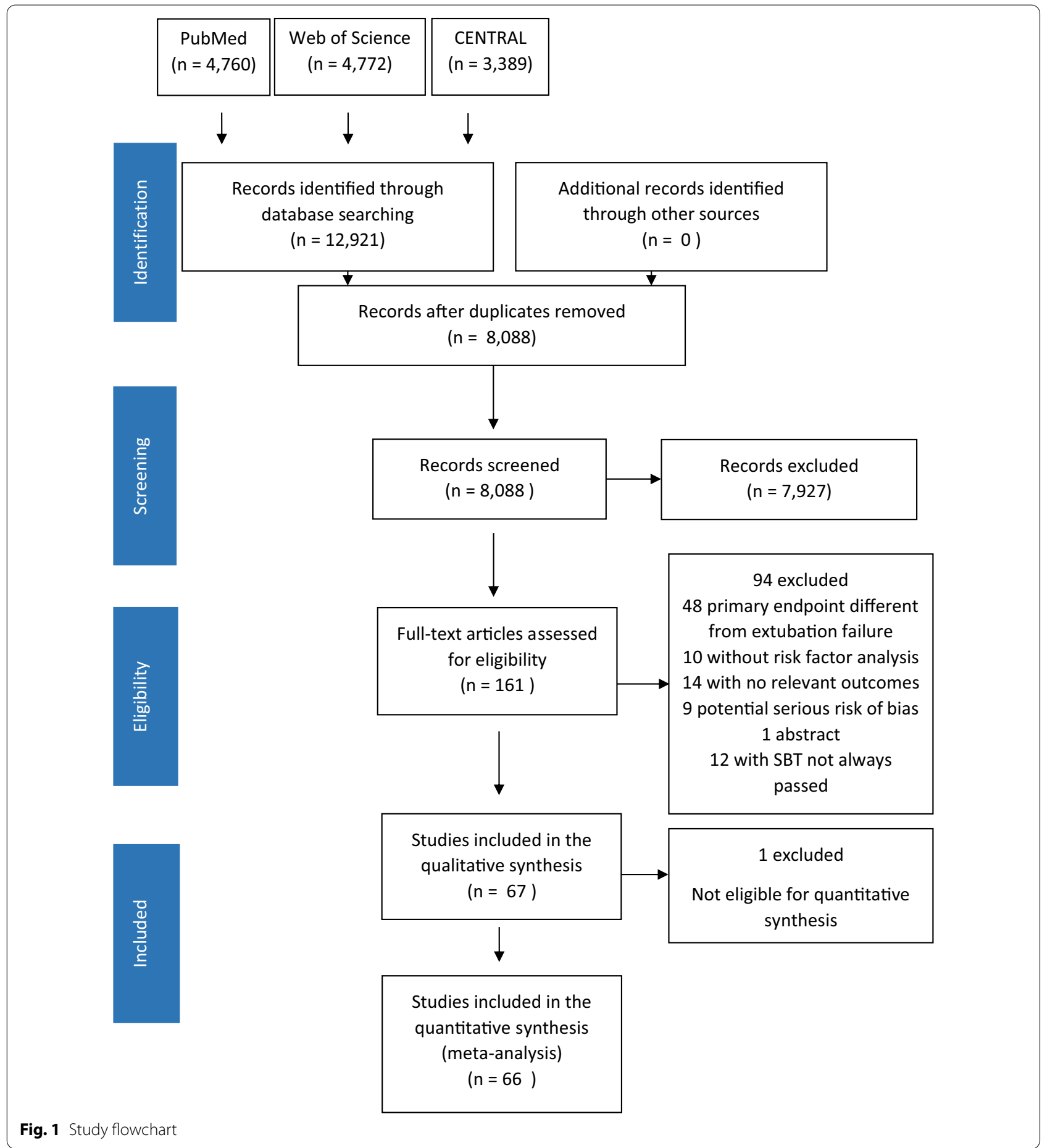

former group. Acute heart failure, COPD exacerbation and pneumonia were the reasons for intubation significantly associated with a higher risk of extubation failure. Duration of mechanical ventilation before extubation was longer in patients with extubation failure.

\section{Characteristics at the time of extubation}

These variables involved the following physiological systems: (1) respiratory: related to secretion management (cough, cough peak flow, maximal expiratory pressure, presence of moderate to abundant secretions, negative 
Table 1 Type of spontaneous breathing trial and definition of extubation failure

\begin{tabular}{lc}
\hline Variable & $\begin{array}{l}\text { Number } \\
\text { of studies } \\
(\%)\end{array}$ \\
& \\
\hline Spontaneous breathing trial & $15(22.4 \%)$ \\
T piece & $6(9.0 \%)$ \\
Low pressure support with zero-end expiratory pressure & $3(4.5 \%)$ \\
Continuous positive airway pressure & $33(49.3 \%)$ \\
Other & $10(14.8 \%)$ \\
Not available & \\
Duration of SBT & $12(17.9 \%)$ \\
30 min & $8(11.9 \%)$ \\
60 min & $13(19.4 \%)$ \\
120 min & $21(31.3 \%)$ \\
Variable* & $12(17.9 \%)$ \\
Not available & \\
Definition of SBT failure & $43(64.2 \%)$ \\
Respiratory rate & $31(46.9 \%)$ \\
Increased breathing work or distress signs & $39(58.2 \%)$ \\
Arterial oxygen saturation & $8(11.9 \%)$ \\
PaO2 & $10(14.9 \%)$ \\
PaCO2 & $11(16.4 \%)$ \\
Tidal volume or minute ventilation or RSBI & $36(53.7 \%)$ \\
Heart rate & $36(53.7 \%)$ \\
Arterial pressure or introduction of vasopressive drug & $38(56.7 \%)$ \\
Neurological criteria & $20(29.9 \%)$ \\
Not available & \\
Definition of extubation failure & \\
Death or reintubation & $10(14.9 \%)$ \\
$\quad$ Within $24 \mathrm{~h}$ & \\
Weintubation or curative non-invasive mechanical ventila- & \\
tion & \\
\hline & Within $72 \mathrm{~h}$
\end{tabular}

SBT spontaneous breathing trial, $\mathrm{PaO} 2$ partial pressure of oxygen, $\mathrm{PaCO} 2$ partial pressure of carbon dioxide, RSBI Rapid Shallow Breathing Index, * from $30 \mathrm{~min}$ to $12 \mathrm{~h}$

inspiratory force), ventilation pattern [respiratory rate and tidal volume before extubation, rapid shallow breathing index (RSBI) after one minute from the SBT start, RSBI before extubation] and oxygenation $\left(\mathrm{SaO}_{2}, \mathrm{PaO}_{2}\right.$ and $\mathrm{PaO}_{2} / \mathrm{FiO}_{2}$ before extubation, hemoglobin on the day of extubation); (2) cardiovascular (heart rate before extubation); and (3) neurological (Glasgow Coma Scale before extubation). The individual topic of secretion management was the one with the largest number variables (five).

\section{Subgroup analysis}

Subgroup analyses according to the type of ICU are presented in Additional file 1: Fig. S2 and Table S2 in the additional material. Among the 49 variables analyzed, 30 were significantly associated with extubation outcome in at least one ICU type. Eight factors were significant in the majority of ICU types (at least three among the five types), including age, SAPS II score, duration of mechanical ventilation before extubation, heart rate, respiratory rate, $\mathrm{RSBI}, \mathrm{PaO}_{2}$ before extubation and cough peak flow. Duration of mechanical ventilation had the broadest association across ICU types (4/5 types), while cough peak flow had the strongest association across ICU types (Additional file 1: Fig. S2).

\section{Sensitivity analysis}

Due to the heterogeneity among studies in terms of definition of extubation failure, we performed an exploratory sensitivity analysis restricted to studies where extubation failure was defined as death or reintubation, whatever the delay (57 out of 67 included in the meta-analysis): the vast majority of variables identified by crude analysis (23) remained significant, while only three were not (see Fig. 2, and Additional file 1: Table S3 in the additional material). Another sensitivity analysis was restricted to studies where extubation failure was defined as death or reintubation within $48 \mathrm{~h}$ (30 articles out of 67 included in the meta-analysis): 15 variables remained significant while eleven were not, including factors related to cough and tracheal secretions (see Fig. 2, and Additional file 1: Table S4 in the additional material).

\section{Multivariable analysis}

The 26 variables significantly associated with extubation outcome were assessed using a multivariable analysis for multiple factors (Additional file 1: Fig. S3 in the additional material). Twelve variables (age, history of cardiac disease, history of respiratory disease, SAPS II score, duration of mechanical ventilation, pneumonia, heart rate, RSBI, negative inspiratory force, lower $\mathrm{PaO}_{2} /$ $\mathrm{FiO}_{2}$, lower Glasgow Coma Scale and lower hemoglobin level before extubation) were retained in the final model (Fig. 3). Glasgow Coma Scale (GCS) before extubation had the strongest independent association with extubation outcome.

\section{Quality}

Included studies differed in their methodological quality (Fig. 4, and Additional file 1: Fig. S4 in the additional material). High risk of bias was related to the study 
Table 2 Variables analyzed in the meta-analysis

\begin{tabular}{|c|c|c|c|c|}
\hline Variables & $n$ & $N$ & Statistical method & Effect estimate $[95 \% \mathrm{Cl}]$ \\
\hline $\mathrm{Age}^{*}$ & 59 & 23,426 & Mean difference & $3.43[2.44,4.41]$ \\
\hline APACHE II score* & 33 & 15,696 & Mean difference & $1.63[0.92,2.35]$ \\
\hline Body mass index* & 13 & 8483 & Mean difference & $-0.64[-1.21,-0.08]$ \\
\hline Male sex & 52 & 22,093 & Odds ratio & $0.90[0.76,1.07]$ \\
\hline SAPS $\|^{*}$ & 15 & 7159 & Mean difference & $4.20[2.75,5.65]$ \\
\hline History of cardiac disease* & 16 & 7298 & Odds ratio & $1.35[1.12,1.64]$ \\
\hline History of respiratory disease* & 11 & 6303 & Odds ratio & $1.49[1.18,1.87]$ \\
\hline $\mathrm{COPD}^{*}$ & 12 & 1984 & Odds ratio & $1.60[1.16,2.21]$ \\
\hline Acute heart failure* & 11 & 3947 & Odds ratio & $1.40[1.04,1.89]$ \\
\hline ARDS & 9 & 2842 & Odds ratio & $1.13[0.75,1.69]$ \\
\hline COPD exacerbation* & 18 & 4183 & Odds ratio & $1.26[1.01,1.58]$ \\
\hline Glasgow Coma Scale before ext.* & 13 & 5933 & Mean difference & $-0.75[-1.06,-0.43]$ \\
\hline Pneumonia* & 17 & 3692 & Odds ratio & $1.48[1.21,1.81]$ \\
\hline Albumin & 9 & 5481 & Mean difference & $-0.21[-0.43,0.02]$ \\
\hline Hemoglobin* & 18 & 7277 & Mean difference & $-0.54[-0.72,-0.35]$ \\
\hline $\mathrm{PaCO}_{2}$ before ext & 34 & 12,328 & Mean difference & $0.81[-0.02,1.64]$ \\
\hline $\mathrm{PaO}_{2}$ before ext.* $^{*}$ & 22 & 9677 & Mean difference & $-8.02[-12.39,-3.66]$ \\
\hline $\mathrm{PaO}_{2} / \mathrm{FiO}_{2}$ before ext.* & 30 & 11,960 & Mean difference & $-19.38[-26.92,-11.84]$ \\
\hline $\mathrm{SaO}_{2}$ before ext.* $^{*}$ & 7 & 1893 & Mean difference & $-0.44[-0.87,-0.01]$ \\
\hline Duration of MV before ext.* & 46 & 19,775 & Mean difference & $1.03[0.62,1.43]$ \\
\hline Respiratory rate before ext.* & 27 & 15,178 & Mean difference & $1.86[1.19,2.54]$ \\
\hline $\mathrm{RSB}^{*}$ & 44 & 20,301 & Mean difference & $8.51[6.20,10.81]$ \\
\hline RSBI after 1 min $\mathrm{SBT}^{*}$ & 8 & 1606 & Mean difference & $10.26[3.68,16.84]$ \\
\hline Tidal volume before ext.* & 25 & 12,070 & Mean difference & $-28.69[-44.61,-12.78]$ \\
\hline Heart rate before ext.* & 20 & 9848 & Mean difference & $2.99[1.49,4.49]$ \\
\hline Maximal expiratory pressure* & 9 & 12,183 & Mean difference & $-10.22[-17.70,-2.73]$ \\
\hline Negative inspiratory force* & 14 & 13,448 & Mean difference & $5.30[3.11,7.48]$ \\
\hline Cough* & 7 & 3337 & Odds ratio & $0.33[0.16,0.66]$ \\
\hline Cough peak flow* & 8 & 1041 & Mean difference & $-27.50[-38.95,-16.04]$ \\
\hline Moderate/abundant secretions* & 7 & 2248 & Odds ratio & $1.98[1.14,3.43]$ \\
\hline Acute respiratory failure & 7 & 1249 & Odds ratio & $1.43[0.88,2.32]$ \\
\hline Coma & 8 & 2742 & Odds ratio & $0.77[0.57,1.03]$ \\
\hline Creatinine & 9 & 5422 & Mean difference & $0.11[-0.06,0.29]$ \\
\hline Diastolic blood pressure before ext & 9 & 1651 & Mean difference & $-1.03[-2.57,0.50]$ \\
\hline Diabetes & 15 & 5976 & Odds ratio & $1.27[0.96,1.69]$ \\
\hline $\mathrm{FiO}_{2}$ during $\mathrm{SBT}$ & 11 & 7818 & Mean difference & $0.00[-0.00,0.01]$ \\
\hline Glasgow Coma Scale upon admission & 14 & 9113 & Mean difference & $-0.28[-0.57,0.00]$ \\
\hline History of hypertension & 8 & 998 & Odds ratio & $1.09[0.78,1.52]$ \\
\hline Mean arterial pressure before ext & 7 & 5161 & Mean difference & $-0.95[-2.36,0.45]$ \\
\hline Minute ventilation before ext & 17 & 14,383 & Mean difference & $0.00[-0.34,0.34]$ \\
\hline Neurologic diagnosis & 9 & 3357 & Odds ratio & $1.19[0.76,1.87]$ \\
\hline PEEP during SBT & 11 & 7214 & Mean difference & $0.05[-0.00,0.10]$ \\
\hline $\mathrm{pH}$ before ext & 27 & 11,392 & Mean difference & $-0.00[-0.01,0.00]$ \\
\hline Postoperative respiratory failure & 7 & 2713 & Odds ratio & $1.01[0.69,1.48]$ \\
\hline SBP before ext & 13 & 5240 & Mean difference & $-0.41[-1.95,1.13]$ \\
\hline Sepsis & 7 & 2903 & Odds ratio & $1.17[0.92,1.48]$ \\
\hline Shock & 8 & 1722 & Odds ratio & $0.87[0.50,1.50]$ \\
\hline Steroids & 7 & 3674 & Odds ratio & $0.84[0.58,1.24]$ \\
\hline Trauma & 7 & 4916 & Odds ratio & $0.83[0.63,1.09]$ \\
\hline
\end{tabular}


Table 2 (continued)

$N$ number of participants, $n$ number of studies, ext extubation, SBT spontaneous breathing trial, SAPS severity acute physiologic score, APACHE acute physiology and chronic health evaluation, $C O P D$ chronic obstructive pulmonary disease, ARDS acute respiratory distress syndrome, $P a C O 2$ partial pressure of carbon dioxide in the arterial blood, $\mathrm{PaO} 2$ partial pressure of oxygen in the arterial blood, $\mathrm{SaO} 2$ oxygen saturation in the arterial blood, FiO2 fraction of inspired oxygen, $\mathrm{RSBI}$ Rapid Shallow Breathing Index, PEEP positive end expiratory pressure, ${ }^{*}$ statistically significant by meta-analysis

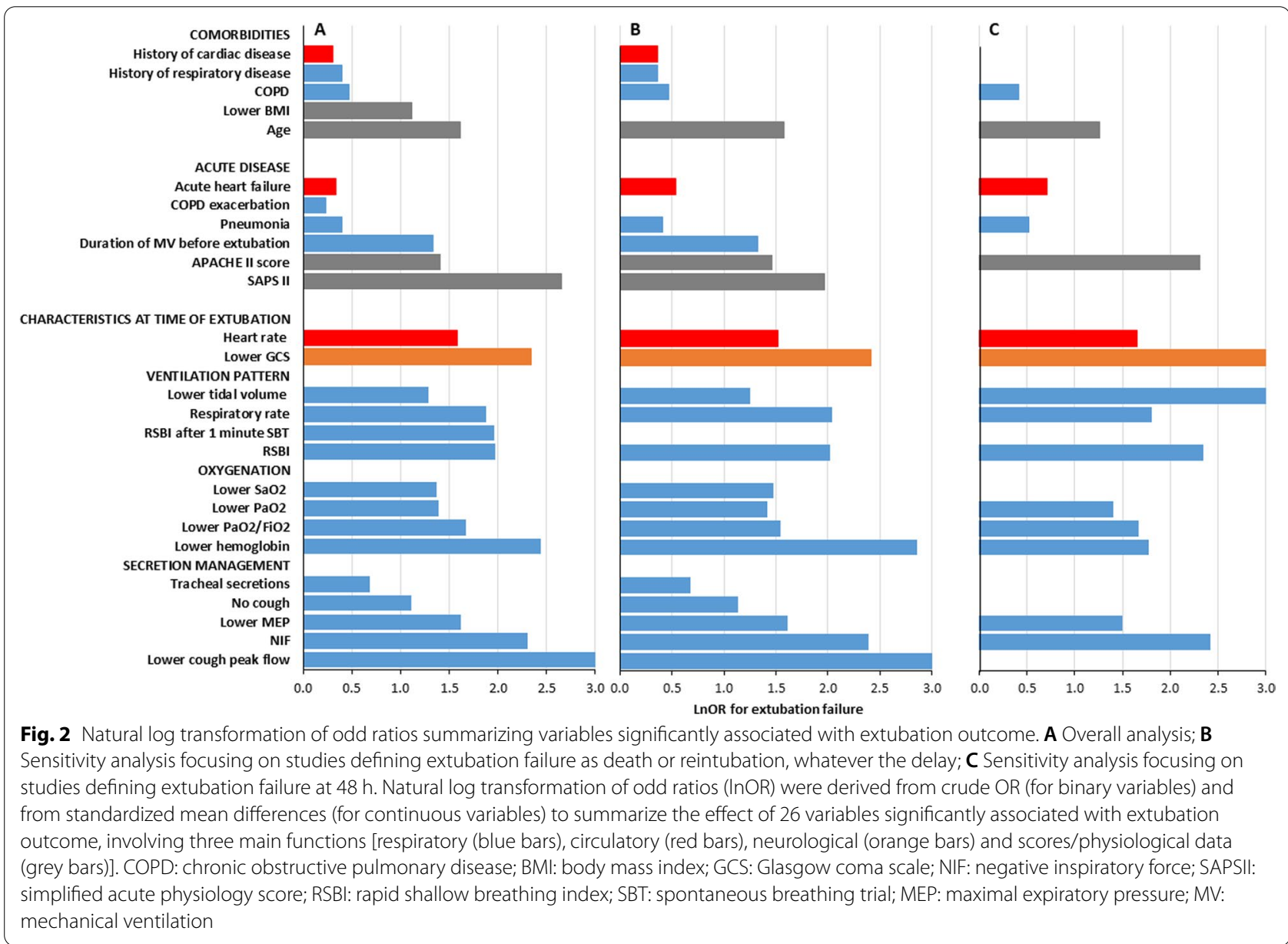

participation in eight studies $[47,57,78-82,85]$, to study attrition in one study [33], to prognostic factor measurement in one study [7], to the outcome measurement in two studies $[29,77]$ and to study confounding in five studies $[27,65,78,81,85]$. The remaining studies had low or unclear risk of bias for each of the six domains.

\section{Discussion}

To the best of our knowledge, we herein report the first meta-analysis on factors associated with extubation failure. By multivariable analysis, twelve factors were significantly associated with extubation failure: age, history of cardiac disease, history of respiratory disease, SAPS II score, duration of mechanical ventilation, pneumonia, heart rate, $\mathrm{RSBI}$, negative inspiratory force, lower $\mathrm{PaO}_{2} /$ $\mathrm{FiO}_{2}$, lower hemoglobin level before extubation and lower Glasgow Coma Scale before extubation, with the latest factor having the strongest independent association with extubation outcome.

\section{Definition of extubation failure}

An important information that comes out from our systematic review is that there is lack of standardization about the definition of extubation failure. It was defined as death or reintubation within a time interval that varies from $24 \mathrm{~h}$ to 7 days and in some studies, it also comprised the need for curative noninvasive ventilation after extubation. This leads to a risk of bias in evaluating 


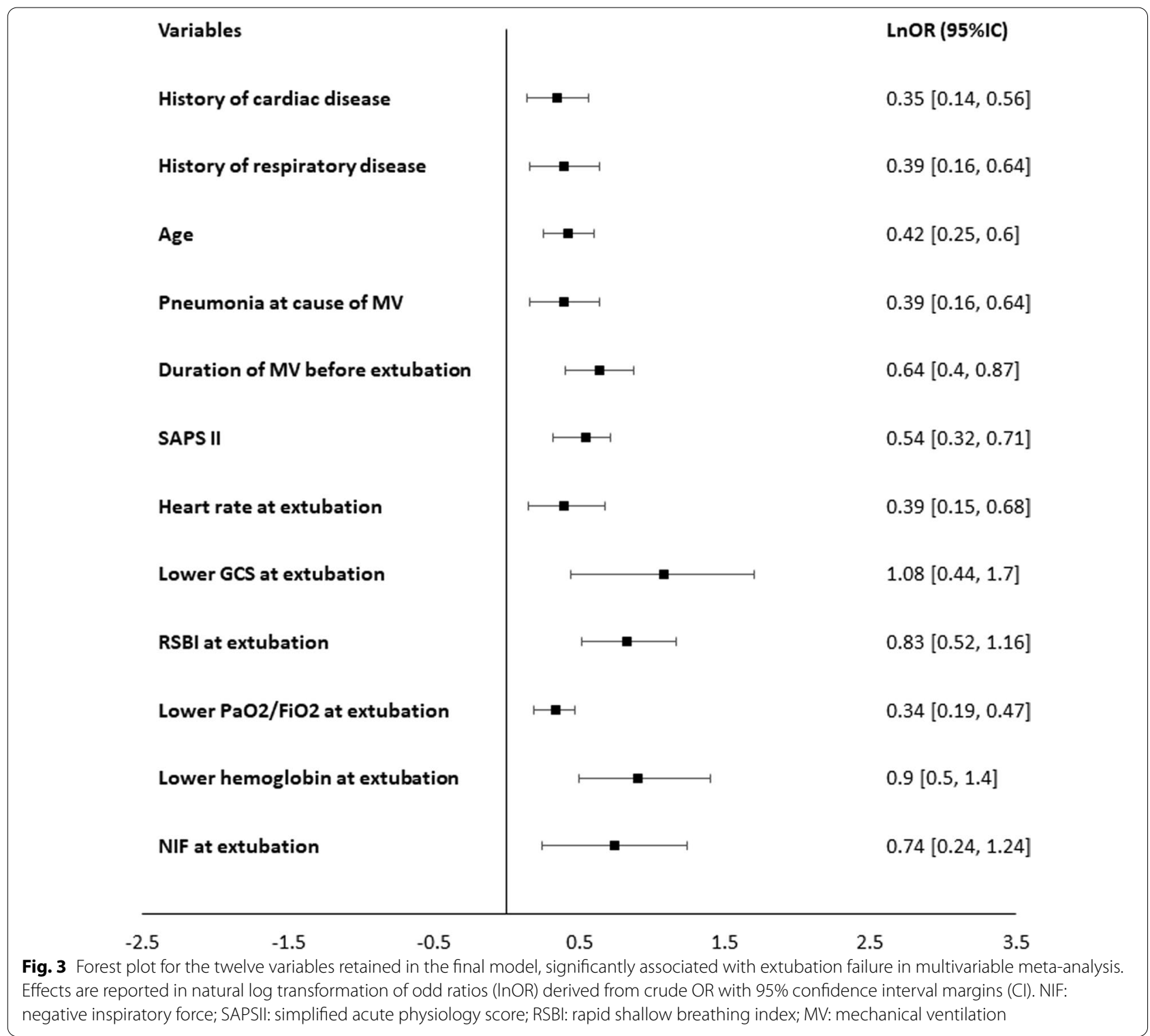

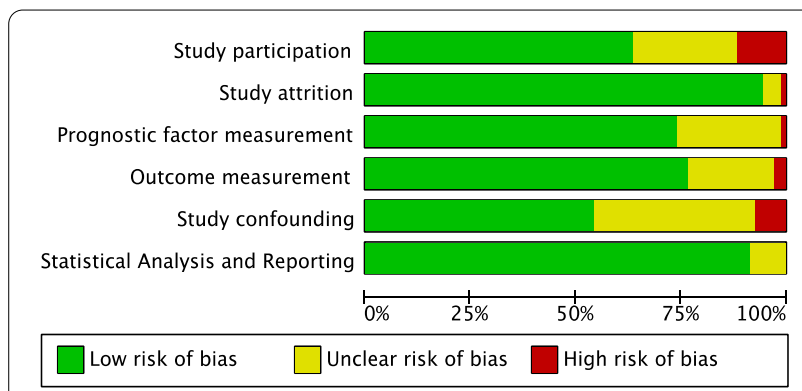

Fig. 4 Summary of risk of bias in the included studies the prognostic factors for extubation failure. For this reason, we performed a sensitivity analysis considering only studies where extubation failure was defined as death or reintubation within $48 \mathrm{~h}$, since this is the most used definition. In this sensitivity analysis, the majority (15 out of 26) of factors identified by the crude analysis remained significant. However, cough, cough peak flow and secretions were no longer associated with extubation outcome when considering a $48 \mathrm{~h}$ delay. Alteration of cough and/or excessive secretions may act as major cause of delayed reintubation. These findings, and the increasing use of prophylactic non-invasive ventilation and high flow oxygen after extubation, may suggest the 
use of death or reintubation within a seven-day delay to define extubation failure in future studies [86].

\section{Risk factors for extubation failure}

As highlighted in the present work, many factors may contribute to extubation failure in a given critically ill patient, suggesting an individual pathophysiological approach. The topic of secretion management was the one with the largest number of variables (five) significantly associated with extubation failure, pointing out that it should be carefully evaluated before extubation. The assessment of the "upper airway patency", in terms of amount of secretions and the ability to clear them through an effective cough, has been increasingly used in the literature, even though these parameters are difficult to measure in an objective and standardized way. Cough peak flow is a parameter that has been proposed in the last few years to overcome this problem, but our multivariable analysis suggests negative inspiratory pressure as a relevant indicator.

Although the majority of statistically significant variables from our meta-analysis were related to the respiratory function (16 variables), the circulatory (three variables) and neurological (one variable) functions were also involved, with Glasgow Coma Scale having the strongest association with extubation outcome by multivariable analysis. These results are consistent with the plurality of often-intertwined mechanisms of extubation failure. Thus, restricting the clinical reasoning to the spectrum of a few variables related to the respiratory function may weaken the decisional process of liberation from mechanical ventilation. Robust multiparametric clinical scores and/or artificial intelligence algorithms should be tested based on the selected variables in order to improve the prediction of extubation outcome in the clinical scenario.

\section{Strengths and limitations}

Strengths of our study include the wide period of assessment and selection process. One limitation is the lack of standardization in the definition of extubation failure. However, we performed a sensitivity analysis using the most accepted definition. Another limitation is that, due to the lack of data, we could not analyze the postextubation stridor, which is considered a rare but important risk factor for extubation failure. Finally, we may have missed other potentially important factors since we chose to analyze only parameters evaluated in at least $10 \%$ of included studies.

\section{Conclusion}

We performed a systematic review and meta-analysis of a wide population of critically ill patients, finding 26 and 12 risk factors for extubation failure in patients who have successfully passed a spontaneous breathing trial by univariate and multivariable analysis, respectively. These factors were related to age, comorbidities, acute disease severity and physiological characteristics at the time of extubation. To further explore these factors and their combination, a unique definition of extubation failure is needed. An automated algorithm incorporating these factors would probably be very useful to inform the decisional process of extubation.

\section{Abbreviations \\ APACHE: Acute physiology and chronic health evaluation; ARDS: Acute respira- tory distress syndrome; BMI: Body mass index; Cl: Confidence interval; COPD: Chronic Obstructive Pulmonary Disease; FiO2: Fraction of inspired oxygen; GCS: Glasgow Coma Scale; ICU: Intensive care unit; IQRs: Interquartile ranges; MEP: Maximal expiratory pressure; MV: Mechanical ventilation; NIF: Negative inspiratory force; OR: Odds ratio; PaCO2: Partial pressure of carbon dioxide in the arterial blood; PaO2: Partial pressure of oxygen in the arterial blood; PEEP: Positive end expiratory pressure; RSBI: Rapid shallow breathing index; SaO2: Oxygen saturation in the arterial blood; SAPS: Severity acute physiologic score; SBT: Spontaneous breathing trial; SD: Standard deviation.}

\section{Supplementary Information}

The online version contains supplementary material available at https://doi. org/10.1186/s13054-021-03802-3.

Additional file 1: Table S1. Variables excluded because of missing data. Figure S1. Forest plots for variables statistically significantly associated with extubation failure. Table S2. Subgroup analyses by intensive care unit type. Figure S2. Heatmap of natural log transformation of odd ratios (LnOR) for extubation failure, according to ICU type. Table S3. Sensitivity analysis focusing on studies defining extubation failure as death or reintubation, whatever the delay. Table S4. Sensitivity analysis focusing on studies defining extubation failure at $48 \mathrm{~h}$. Figure $\mathbf{S 3}$. Individual risk of bias in the included studies. Figure S4. Forest plot for the 26 variables significantly associated with extubation failure, assessed by multivariate meta-analysis for multiple factors.

\section{Acknowledgements}

Not applicable.

\section{Authors' contributions}

AMD, FT and JM designed the meta-analysis. FT and JM searched for the articles, screened titles and abstracts and extracted data. AMD, FT and SG performed statistical analysis and interpretation of data. AWT, GC and MA contributed to the conception of the study. FT and AMD drafted the manuscript, and $\mathrm{FT}, \mathrm{SG}, \mathrm{JM}, \mathrm{GC}, \mathrm{AWT}, \mathrm{MA}$ and $\mathrm{AMD}$ revised it for important intellectual content; all authors read and approved the final manuscript.

\section{Funding}

None.

Availability of data and materials Data sharing is not applicable to this article as no datasets were generated or analyzed during the current study. 


\section{Declarations}

Ethics approval and consent to participate

Not applicable.

\section{Consent for publication}

Not applicable.

\section{Competing interests}

The authors declare that they have no competing interests.

\section{Author details}

${ }^{1}$ Service de Médecine Intensive Réanimation, Hôpitaux Universitaires Henrì Mondor, AP-HP, 1 rue Gustave Eiffel, 94010 Créteil Cedex, France. ${ }^{2}$ CARMAS, Univ Paris Est Créteil, 94010 Créteil, France. ${ }^{3}$ INSERM, IMRB, Univ Paris Est Créteil, 94010 Créteil, France. ${ }^{4}$ Centre d'Investigation Clinique 1402 ALIVE, Université de Poitiers, Poitiers, France. ${ }^{5}$ Service de Médecine Intensive Réanimation, Centre Hospitalier Universitaire de Poitiers, Poitiers, France. ${ }^{6}$ Fondazione Policlinico Universitario A. Gemelli IRCCS, Rome, Italy.

Received: 20 July 2021 Accepted: 24 October 2021

Published online: 15 November 2021

\section{References}

1. Bigatello LM, Stelfox HT, Berra L, Schmidt U, Gettings EM. Outcome of patients undergoing prolonged mechanical ventilation after critical illness. Crit Care Med. 2007;35:2491-7.

2. Boles J-M, Bion J, Connors A, Herridge M, Marsh B, Melot C, et al. Weaning from mechanical ventilation. Eur Respir J. 2007;29:1033-56.

3. Ely EW, Baker AM, Dunagan DP, Burke HL, Smith AC, Kelly PT, et al. Effect on the duration of mechanical ventilation of identifying patients capable of breathing spontaneously. N Engl J Med. 1996;335:1864-9.

4. Segal LN, Oei E, Oppenheimer BW, Goldring RM, Bustami RT, Ruggiero S, et al. Evolution of pattern of breathing during a spontaneous breathing trial predicts successful extubation. Intensive Care Med. 2010;36:487-95.

5. Beigmohammadi MT, Khan ZH, Samadi S, Mahmoodpoor A, Fotouhi A, Rahimiforoushani A, et al. Role of hematocrit concentration on successful extubation in critically ill patients in the intensive care units. Anesthesiol Pain Med. 2016. https://doi.org/10.5812/aapm.32904.

6. Su WL, Chen YH, Chen CW, Yang SH, Su CL, Perng WC, et al. Involuntary cough strength and extubation outcomes for patients in an ICU. Chest. 2010;137:777-82

7. Miu T, Joffe AM, Yanez ND, Khandelwal N, Dagal AH, Deem S, et al. Predictors of reintubation in critically ill patients. Respir Care. 2014;59:178-85.

8. Thille AW, Richard JCM, Brochard L. The decision to extubate in the intensive care unit. Am J Respir Crit Care Med. 2013;187:1294-302.

9. Thille AW, Harrois A, Schortgen F, Brun-Buisson C, Brochard L. Outcomes of extubation failure in medical intensive care unit patients. Crit Care Med. 2011;39:2612-8.

10. Esteban A, Alía I, Tobin MJ, Gil A, Gordo F, Vallverdú I, et al. Effect of spontaneous breathing trial duration on outcome of attempts to 1999discontinue mechanical ventilation. Spanish Lung Failure Collaborative Group. Am J Respir Crit Care Med. 1999;159:512-18.

11. Vallverdú I, Calaf N, Subirana M, Net A, Benito S, Mancebo J. Clinical characteristics, respiratory functional parameters, and outcome of a two-hour T-piece trial in patients weaning from mechanical ventilation. Am J Respir Crit Care Med. 1998;158:1855-62.

12. Frutos-Vivar F, Ferguson ND, Esteban A, Epstein SK, Arabi Y, Apezteguía C, et al. Risk factors for extubation failure in patients following a successful spontaneous breathing trial. Chest. 2006;130:1664-71.

13. Frutos-Vivar F, Esteban A, Apezteguia C, González M, Arabi Y, Restrepo Ml, et al. Outcome of reintubated patients after scheduled extubation. J Crit Care. 2011;26:502-509.

14. Kollef MH, Shapiro SD, Silver P, St. John RE, Prentice D, Sauer S, et al. A randomized, controlled trial of protocol-directed versus physician- directed weaning from mechanical ventilation. Crit Care Med. 1997;25:567-74.
15. Saura P, Blanch L, Mestre J, Vallés J, Artigas A, Fernández R. Clinical consequences of the implementation of a weaning protocol. Intensive Care Med. 1996:22:1052-6.

16. Moher D, Liberati A, Tetzlaff J, Altman DG. Preferred reporting items for systematic reviews and meta-analyses: the PRISMA statement. PLoS Med. 2009;6:e1000097

17. Wan X, Wang W, Liu J, Tong T. Estimating the sample mean and standard deviation from the sample size, median, range and/or interquartile range. BMC Med Res Methodol. 2014. https://doi.org/10.1186/ 1471-2288-14-135.

18. Higgins J, Thomas J, Chandler J, Cumpston M, Li T, Page M, et al. Cochrane handbook for systematic reviews of interventions. 2nd ed. Chichester: Wiley; 2019.

19. Higgins J, Thomas J, Deeks J. Chapter 6: Choosing effect measures and computing estimates of effect. Cochrane handbook systematic review interventions version 62 update Feb 2021. Chichester: Wiley; 2019.

20. Higgins JPT, Thompson SG. Quantifying heterogeneity in a meta-analysis. Stat Med. 2002;21:1539-58.

21. Riley RD, Higgins JPT, Deeks JJ. Interpretation of random effects metaanalyses. BMJ. 2011;342:d549.

22. Chinn S. A simple method for converting an odds ratio to effect size for use in meta-analysis. Stat Med. 2000;19:3127-31.

23. Lin L, Chu H. Bayesian multivariate meta-analysis of multiple factors. Res Synth Methods. 2018:9:261-72.

24. Riley RD, Thompson JR, Abrams KR. An alternative model for bivariate random-effects meta-analysis when the within-study correlations are unknown. Biostatistics. 2008:9:172-86.

25. Egger M, Smith GD, Schneider M, Minder C, Tabuso M, Dunlop A, et al. Bias in meta-analysis detected by a simple, graphical test. BMJ. 1997;315:629-34

26. Liu Y, Wei LQ, Li GQ, Lv FY, Wang H, Zhang YH, et al. A decisiontree model for predicting extubation outcome in elderly patients after a successful spontaneous breathing trial. Anesth Analg. 2010;111:1211-8.

27. White CE, Batchinsky Al, Necsoiu C, Nguyen R, Walker KP, Chung KK, et al. Lower interbreath interval complexity is associated with extubation failure in mechanically ventilated patients during spontaneous breathing trials. J Trauma Inj Infect Crit Care. 2010;68:1310-6.

28. Seely AJE, Bravi A, Herry C, Green G, Longtin A, Ramsay T, et al. Erratum to: Do heart and respiratory rate variability improve prediction of extubation outcomes in critically ill patients? Crit Care. 2014. https:// doi.org/10.1186/s13054-014-0620-z.

29. Brown CVR, Daigle JB, Foulkrod KH, Brouillette B, Clark A, Czysz C, et al. Risk factors associated with early reintubation in trauma patients: a prospective observational study. J Trauma Inj Infect Crit Care. 2011:71:37-42

30. Thille AW, Boissier F, Ghezala HB, Razazi K, Mekontso-Dessap A, Brun-Buisson C. Risk factors for and prediction by caregivers of extubation failure in ICU patients: a prospective study. Crit Care Med. 2015:43:613-20.

31. Duan J, Zhou L, Xiao M, Liu J, Yang X. Semiquantitative cough strength score for predicting reintubation after planned extubation. Am J Crit Care. 2015;24:e86-90

32. Colonel P, Houzé MH, Vert H, Mateo J, Mégarbane B, Goldgran-Tolédano $D$, et al. Swallowing disorders as a predictor of unsuccessful extubation: a clinical evaluation. Am J Crit Care. 2008;17:504-10.

33. Boniatti VM, Boniatti MM, Andrade CF, Zigiotto CC, Kaminski P, Gomes SP, et al. The modified integrative weaning index as a predictor of extubation failure. Respir Care. 2014;59:1042-7.

34. Fujii E, Fujino K, Tanaka-Mizuno S, Eguchi Y. Variation of risk factors for cause-specific reintubation: a preliminary study. Can Respir J. 2018;2018:3654251

35. Dos Reis HFC, Almeida MLO, Da Silva MF, Moreira JO, De Seixas RM. Associação entre o índice de respiração rápida e superficial e o sucesso da extubação em pacientes com traumatismo cranioencefálico. Rev Bras Ter Intensiva. 2013;25:212-7.

36. Teixeira C, Da Silva NB, Savi A, Vieira SRR, Nasi LA, Friedman G, et al. Central venous saturation is a predictor of reintubation in difficult-to-wean patients. Crit Care Med. 2010;38:491-6. 
37. Chien JY, Lin MS, Huang YCT, Chien YF, Yu CJ, Yang PC. Changes in B-type natriuretic peptide improve weaning outcome predicted by spontaneous breathing trial. Crit Care Med. 2008;36:1421-6.

38. Smailes ST, McVicar AJ, Martin R. Cough strength, secretions and extubation outcome in burn patients who have passed a spontaneous breathing trial. Burns. 2013;39:236-42.

39. dos Reis HFC, Gomes-Neto M, Almeida MLO, da Silva MF, Guedes LBA, Martinez BP, et al. Development of a risk score to predict extubation failure in patients with traumatic brain injury. J Crit Care. 2017;42:218-22.

40. Thille AW, Boissier F, Ben-Ghezala H, Razazi K, Mekontso-Dessap A, BrunBuisson C, et al. Easily identified at-risk patients for extubation failure may benefit from noninvasive ventilation: a prospective before-after study. Crit Care. 2016. https://doi.org/10.1186/s13054-016-1228-2.

41. El Solh AA, Bhat A, Gunen H, Berbary E. Extubation failure in the elderly. Respir Med. 2004;98:661-8.

42. Fernandez R, Raurich JM, Mut T, Blanco J, Santos A, Villagra A. Extubation failure: diagnostic value of occlusion pressure (P0.1) and P0.1-derived parameters. Intensive Care Med. 2004;30:234-40.

43. Jaber S, Quintard H, Cinotti R, Asehnoune K, Arnal J-M, Guitton C, et al. Risk factors and outcomes for airway failure versus non-airway failure in the intensive care unit: a multicenter observational study of 1514 extubation procedures. Critical Care. 2018. https://doi.org/10.1186/ s13054-018-2150-6.

44. Asehnoune K, Seguin P, Lasocki S, Roquilly A, Delater A, Gros A, et al. Extubation success prediction in a multicentric cohort of patients with severe brain injury. Anesthesiology. 2017;127:338-46.

45. Hayashi LY, Gazzotti MR, Vidotto MC, Jardim JR. Incidence, indication and complications of postoperative reintubation after elective intracranial surgery. Sao Paulo Med J. 2017;131:158-65.

46. Norisue Y, Kataoka J, Homma Y, Naito T, Tsukuda J, Okamoto K, et al. Increase in intra-abdominal pressure during airway suctioning-induced cough after a successful spontaneous breathing trial is associated with extubation outcome. Ann Intensive Care. 2018. https://doi.org/10.1186/s13613-018-0410-x.

47. Seymour CW, Halpern S, Christie JD, Gallop R, Fuchs BD. Minute ventilation recovery time measured using a new, simplified methodology predicts extubation outcome. J Intensive Care Med. 2008:23:52-60.

48. Martinez A, Seymour C, Nam M. Minute ventilation recovery time: a predictor of extubation outcome. Chest. 2003;123:1214-21.

49. Takaki S, Kadiman SB, Tahir SS, Ariff MH, Kurahashi K, Goto T. Modified rapid shallow breathing index adjusted with anthropometric parameters increases predictive power for extubation failure compared with the unmodified index in postcardiac surgery patients. J Cardiothorac Vasc Anesth. 2015;29:64-8.

50. Salam A, Tilluckdharry L, Amoateng-Adjepong Y, Manthous CA. Neurologic status, cough, secretions and extubation outcomes. Intensive Care Med. 2004:30:1334-9.

51. Banner MJ, Euliano NR, Martin AD, Al-Rawas N, Layon AJ, Gabrielli A. Noninvasive work of breathing improves prediction of post-extubation outcome. Intensive Care Med. 2012;38:248-55.

52. Tadié JM, Behm E, Lecuyer L, Benhmamed R, Hans S, Brasnu D, et al. Postintubation laryngeal injuries and extubation failure: a fiberoptic endoscopic study. Intensive Care Med. 2010;36:991-8.

53. Mokhlesi B, Tulaimat A, Gluckman TJ, Wang Y, Evans AT, Corbridge TC. Predicting extubation failure after successful completion of a spontaneous breathing trial. Respir Care. 2007:52:1710-7.

54. Gobert F, Yonis H, Tapponnier R, Fernandez R, Labaune M-A, Burle J-F, et al. Predicting extubation outcome by cough peak flow measured using a built-in ventilator flow meter. Respir Care. 2017;62:1505-19.

55. Piriyapatsom A, Williams EC, Waak K, Ladha KS, Eikermann M, Schmidt UH. Prospective observational study of predictors of re-intubation following extubation in the surgical ICU. Respir Care. 2016;61:306-15.

56. Kutchak FM, Debesaitys AM, Rieder MM, Meneguzzi C, Skueresky AS, Forgiarini LA, et al. Reflex cough PEF as a predictor of successful extubation in neurological patients. J Bras Pneumol. 2015;41:358-64.

57. Ibrahim AS, Aly MG, Abdel-Rahman KA, Mohamed MA, Mehany MM, Aziz EM. Semi-quantitative cough strength score as a predictor for extubation outcome in traumatic brain injury: a prospective observational study. Neurocrit Care. 2018:29:273-9.

58. Kutchak FM, Rieder MM, Victorino JA, Meneguzzi C, Poersch K, Forgiarini LA, et al. Simple motor tasks independently predict extubation failure in critically ill neurological patients. J Bras Pneumol. 2017;43:183-9.
59. Hernandez Martinez G, Fernandez R, Luzon E, Cuena R, Montejo JC. The early phase of the minute ventilation recovery curve predicts extubation failure better than the minute ventilation recovery time. Chest. 2007;131:1315-22.

60. Steidl C, Boesel J, Suntrup-Krueger S, Schoenenberger S, Al-Suwaidan F, Warnecke T, et al. Tracheostomy, extubation, reintubation: airway management decisions in intubated stroke patients. Cerebrovasc Dis. 2017:44:1-9.

61. Bai L, Duan J. Use of cough peak flow measured by a ventilator to predict re-intubation when a spirometer is unavailable. Respir Care. 2017;62:566-71.

62. Savi A, Teixeira C, Silva JM, Borges LG, Pereira PA, Pinto KB, et al. Weaning predictors do not predict extubation failure in simple-to-wean patients. J Crit Care. 2012;27:221.e1-221.e8.

63. McCredie VA, Ferguson ND, Pinto RL, Adhikari NKJ, Fowler RA, Chapman $M G$, et al. Airway management strategies for brain-injured patients meeting standard criteria to consider extubation: a prospective cohort study. Ann Am Thorac Soc. 2017;14:85-93.

64. Godet T, Chabanne R, Marin J, Kauffmann S, Futier E, Pereira B, et al. Extubation failure in brain-injured patients. Anesthesiology. 2017;126:104-14.

65. Farghaly S, Hasan AA. Diaphragm ultrasound as a new method to predict extubation outcome in mechanically ventilated patients. Aust Crit Care. 2017;30:37-43.

66. Liu Y, MuY, Li GQ, Yu X, Li PJ, Shen ZQ, et al. Extubation outcome after a successful spontaneous breathing trial: a multicenter validation of a 3-factor prediction model. Exp Ther Med. 2015;10:1591-601.

67. Kuo H-J, Chiu H-W, Lee C-N, Chen T-T, Chang C-C, Bien M-Y. Improvement in the prediction of ventilator weaning outcomes by an artificial neural network in a medical ICU. Respir Care. 2015;60:1560-9.

68. Teixeira C, Zimermann Teixeira PJ, Hohër JA, de Leon PP, Brodt SFM, da Siva MJ. Serial measurements of $\mathrm{f} N \mathrm{~T}$ can predict extubation failure in patients with f $/ N T \leq 105$ ? J Crit Care. 2008;23:572-6.

69. Xiao M, Duan J. Weaning attempts, cough strength and albumin are independent risk factors of reintubation in medical patients. Clin Respir J. 2018;12:1240-6.

70. Menon N, Joffe AM, Deem S, Yanez ND, Grabinsky A, Dagal AH, et al. Occurrence and complications of tracheal reintubation in critically ill adults. Respir Care. 2012;57:1555-63.

71. Hsieh M-H, Hsieh M-J, Chen C-M, Hsieh C-C, Chao C-M, Lai C-C. An artificial neural network model for predicting successful extubation in intensive care units. J Clin Med. 2018;7:240.

72. Yoo JW, Lee SJ, Lee JD, Kim HC. Comparison of clinical utility between diaphragm excursion and thickening change using ultrasonography to predict extubation success. Korean J Intern Med. 2018;33:331-9.

73. Chao CM, Lai CC, Cheng AC, Chiang SR, Liu WL, Ho CH, et al. Establishing failure predictors for the planned extubation of overweight and obese patients. PLoS ONE. 2017;12(8):e0183360.

74. Lai CC, Chen CM, Chiang SR, Liu WL, Weng SF, Sung Ml, et al. Establishing predictors for successfully planned endotracheal extubation. Med U S. 2016;95(41):e4852.

75. Nantsupawat N, Nantsupawat T, Limsuwat C, Sutamtewagul G, Nugent K. Factors associated with reintubation in patients with chronic obstructive pulmonary disease. Qual Manag Health Care. 2015;24:200-6.

76. Silva C, Timenetsky K, Taniguchi C, Calegaro S, Azevedo C, Stus R, et al. Low mechanical ventilation times and reintubation rates associated with a specific weaning protocol in an intensive care unit setting: a retrospective study. Clinics. 2012;67:995-1000

77. Saugel B, Rakette P, Hapfelmeier A, Schultheiss C, Phillip V, Thies P, et al. Prediction of extubation failure in medical intensive care unit patients. J Crit Care. 2012:27:571-7.

78. Guru PK, Singh TD, Pedavally S, Rabinstein AA, Hocker S. Predictors of extubation success in patients with posterior fossa strokes. Neurocrit Care. 2016;25:117-27.

79. Mahmood S, Alani M, Al-Thani H, Mahmood I, El-Menyar A, Latifi R. Predictors of re-intubation in trauma intensive care unit: Qatar experience. Oman Med J. 2014:29:289-93.

80. Dupont H, Le Port Y, Paugam-Burtz C, Mantz J, Desmonts J. Reintubation after planned extubation in surgical ICU patients: a case-control study. Intensive Care Med. 2001;27:1875-80.

81. Wojak JF, Ditz C, Abusamha A, Smith E, Gliemroth J, Tronnier V, et al. The impact of extubation failure in patients with good-grade subarachnoid hemorrhage. World Neurosurg. 2018;117:e335-40. 
82. El Khoury MY, Panos RJ, Ying J, Almoosa KF. Value of the $\mathrm{PaO}_{2}: \mathrm{FiO}_{2}$ ratio and Rapid Shallow Breathing Index in predicting successful extubation in hypoxemic respiratory failure. Heart Lung J Acute Crit Care. 2010;39:529-36.

83. Okabe Y, Asaga T, Bekku S, Suzuki H, Kanda K, Yoda T, et al. Lung-thorax compliance measured during a spontaneous breathing trial is a good index of extubation failure in the surgical intensive care unit: a retrospective cohort study. J Intensive Care. 2018. https://doi.org/10.1186/s40560-018-0313-9.

84. Robriquet L, Georges H, Leroy O, Devos P, D'escrivan T, Guery B. Predictors of extubation failure in patients with chronic obstructive pulmonary disease. J Crit Care. 2006;21:185-90.

85. Segura A, Carvajal N, Chavarro PA, Wilches EC, Carvajal A. Sensitivity and specificity of the Yang Tobin Index to predict extubation success in critical patients. Colomb Med. 2011;42:458-67.
86. Béduneau G, Pham T, Schortgen F, Piquilloud L, Zogheib E, Jonas M, et al. Epidemiology of weaning outcome according to a new definition. The WIND study. Am J Respir Crit Care Med. 2017;195:772-83.

\section{Publisher's Note}

Springer Nature remains neutral with regard to jurisdictional claims in published maps and institutional affiliations.
Ready to submit your research? Choose BMC and benefit from:

- fast, convenient online submission

- thorough peer review by experienced researchers in your field

- rapid publication on acceptance

- support for research data, including large and complex data types

- gold Open Access which fosters wider collaboration and increased citations

- maximum visibility for your research: over $100 \mathrm{M}$ website views per year

At BMC, research is always in progress.

Learn more biomedcentral.com/submissions 